0022-3956(93)E0008-Z

\title{
RISK FACTORS FOR ANABOLIC-ANDROGENIC STEROID USE IN MEN
}

\author{
Kirk J. Brower, Frederic C. Blow and Elizabeth M. Hill \\ Department of Psychiatry and Alcohol Research Center. University of Michigan. Ann Arbor. \\ Michigan. U.S.A.
}

(Recerved for publication 19 November 1993)

\begin{abstract}
Summary -The illicit use of anabolic steroids to enhance athletic performance and physical appearance can cause numerous psychiatric and other adverse effects. In order to prevent steroid use and its negative consequences, knowledge of risk factors is needed. We conducted an anonymous survey of 404 male weight lifters from community gymnasiums who completed a 20 -min, self-administered questionnaire. The sample for this study included all $35 \mathrm{men}$ who were thinking about using steroids ("high-risk" nonusers), 50 randomly selected nonusers who were not thinking about using steroids ("low-risk" nonusers) and all 49 steroid users. The three groups differed in age, training characteristics, other performance-enhancers tried, body image. acquaintance with steroid users, and perception of negative consequences. When groups were compared along a continum from low risk to high risk and from high risk to actual use, we found increasing amounts of competitive bodybuilding, performance-enhancers tried, and steroid-using acquaintances. Groups did not differ in their use of addictive substances. Nearly three-fourths of the high-risk group felt "not big enough." compared to $21 \%$ of the low-risk group and $38 \%$ of the steroid users $(p<.001)$. These data suggest that steroids do work to increase satisfaction with body size. and that dissatisfaction with body size may contribute to the risk of using steroids.
\end{abstract}

\section{Introduction}

ANABOLIC-ANDROGENIC steroids, including testosterone and its synthetic derivatives, are used illicitly to enhance athletic performance and physical appearance. An estimated 1 million Americans have tried anabolic-androgenic steroids (Yesalis et al., 1993). As evidence of widespread use increases, particularly among adolescents and young adults (Yesalis, 1992), so do concerns about the potential of these drugs to cause adverse health consequences (Council on Scientific Affairs, 1990). Psychiatric effects have been associated with using steroids, including depression, suicides, mania, psychosis, marked aggression and homicidal violence (so-called "roid rage"), and addiction (Bahrke et al., 1990; Brower, 1992; Su et al., 1993). A particularly alarming trend in some adolescents has been the use of shared needles for injecting steroids (DuRant et al., 1993).

In order to prevent steroid use and its negative consequences, knowledge of risk factors

Correspondence to: Dr Brower, University of Michigan Alcohol Research Center, 400 E. Eisenhower, Suite A, Ann Arbor, MI 48104, U.S.A., Tel. 313-998-7952; Fax 313-998-7994.

Presented in part at the Annual Meeting of the American Psychiatric Association in New York. NY, in May 1990. 
is needed so that prevention programs can target the risk factors to reduce steroid use. Cross-sectional studies that compare users and nonusers of steroids represent one approach to delineating risk factors for use. Studies of high school and college students have found that males are more likely to use steroids than females and athletes are more likely to use steroids than nonathletes (Buckley et al.. 1988: DuRant et al., 1993: Yesalis. 1992). Buckley et al. (1988). in their survey of male high school seniors, found that steroid users were more likely to participate in school sports, to be slightly older. to have a racial minority status. to be from larger schools, and to have parents who had not completed high school. In a national survey of the general population, males were significantly more likely than females to have tried steroids, but significant racial differences in steroid use were not observed (Yesalis et al.. 1993). Taken together. these studies point to the importance of sociodemographic fictors as cont ributors to the risk of using steroids

Training chatacteristics may also be important determinants of steroid use. Pope ed al. (1988) found that colleglate steroid users spent more time training with weights than nonusers. The role of other drug use as a predictor of steroid-laking is poorly studied. Whereas alcohol, tobacco, and marijuatna may be "gateway drugs" for steroid use as they are for other illicit drugs it is equally possible that steroids are themselves gateway drugs: i.e. once an exereise-oriented person has crossed the threshold lor illicit steroid use. then other illicit drugs might more likely be used. Krowchuk et al. (1989) reported that illicit drug-using high school athletes were more likely to be aware of steroids and to regard them ats eflicacious, but were no more likely to be considering their use. Pope et al. (1988) found that college-age steroid users were more likely than nonusers to use cigarettes. alcohol. and illicit drugs. although the small number of users in their study precluded statistical tests of significance. DuRant et al. (1993) found that the use of anabolic steroids was significantly correlated with the frequency of use of cocaline, marijuana. and smokeless tobateco in adolescents. Finally. Yesalis et al. 1993), in the national survey of steroid use across age groups, found significant associations between steroid use and both the use of other illicit drugs and the use of alcohol. However. the association between cigatelte use and steroid use was signilicant only for the 1217 year old group.

Some individuals may initiate steroid use beciluse they are either competing with their peers (as with athletes) or trying 10 increase their social desirability and attractiveness among their pecrs. Prior to using steroids. they may leel that they do not "meatsure up" or that they are not big enough. Thus. body image is a potential factor to study (Komoroski \& Rickert. 1992). Hatring steroid-using acguaintances maly also influence steroid use. Finally, pereeived risks of drug-taking may influence the tendency to use steroids, ats it apparently does for coeatine (Bachman et al.. 1990).

The following study was conducted to determine if a community sample of steroid-using and nonusing weight lifters differed in terms of demographics. raining characteristics. other substance use, body image. steroid-using acquaintances. and negative pereeptions of steroids. We assumed that nonusers who were thinking about using steroids in the future had a higher risk of future steroid use (high-risk group) than nonusers who were not thinking about using steroids (low-risk group). Therefore, we compared high-risk nonusers to both low-risk nomusers and steroid users to identify possible differences and risk fictors. 
Methods

\section{Subjects}

Subjects were member weight lifters of four community gymnasiums who agreed to complete a self-administered questionnaire. Written informed consent was previously obtained from the gym owners or managers to distribute the questionnaire on-site. Owners/managers were assured that the name of their gym and other identifying information would be kept confidential and would not be linked to results or publications. Four gymnasiums were selected because of their convenience, and none refused participation. The study was conducted after obtaining approval from the appropriate Institutional Review Board of the University of Michigan.

Over a 7-month period ending in November 1989.449 questionnatires were collected from weight lifters, including 45 females $(10 \%)$. Because there were only two female steroid users and just one woman who indicated that she might try steroids in the future. we excluded women from the analyses. Of the 404 surveys from men, 49 (12\%) admitted to using steroids and four men $(1 \%)$ could not be classified because of incomplete responses. Of the 351 non-using men, 319 answered the following question: "Do you think you would ever try anabolic steroids in the future?" (Of the 32 nonusers who did not answer the question for defining risk, 29 completed an earlier version of the questionnaire without this question and 3 did not respond.) If they answerce "yes," they were defined as high-risk nonusers. If they answered "no," they were defined as loll-risk nonusers. On this basis, 35 $(11 \%)$ men were high-risk nonusers and $284(89 \%)$ men were low-risk nonusers. Of the 284 low-risk nonusers, 50 were randomly chosen by computer to form a similarly sized comparison group for statistical analyses. Similarly sized groups were important to fulfill the assumption of equal variances for the analyses of variance.

In sum, we divided the sample of men into three comparison groups. All 49 steroid users constituted the first group. Addictive patterns of steroid use in these 49 males were analyzed in a previous report, but comparisons with nonusers were not studied (Brower et al., 1991). All 35 high-risk nonusers (those who indicated that they might try steroids in the future) constituted the second group, and 50 low-risk nonusers (those who were not thinking about trying steroids) constituted the third group.

\section{The questionnaire}

The questionnaire, entitled "The University of Michigan Weight Lifter"s Survey", was designed to be self-administered in $15.20 \mathrm{~min}$. The questionnaire obtained information about demographic variables. patterns of weight lifting. body image, and patterns of steroid and other drug use. The length of the questionnaire was balanced for users and nonusers by a branch point which directed nonusers to answer a unique set of questions including their perceptions of and access to steroids, and which directed users to answer specific questions about their steroid use. Thus, some data presented below were available for the nonusers only. Subjects were asked by research assistants to complete the questionnaire either before or alter their workouts. The front page contained instructions that explained the purpose of the questionnaire and gave assurance about anonymity. Subjects were instructed not to put their names on the questionnaire and to return the questionnaire 
inside a sealed envelope. The envelopes were returned from the gym by the research assistants and opened at a later date. Those opening the questionnaires did not know from which gymnasium they came or who filled them out. Subjects" willingness to return the questionnaire constituted their consent to participate in the study.

The clarity of the questionnaire was tested in a pilot sample by face-to-face intervicws in five subjects. Urine testing was performed in one pilot subject. In all tested instances. the subjects' responses were confirmed. In addition, reliability coeflicients for two repeated questions for the 134 subjects were high (Pearson $r=0.99 . p<.001$ and Pearson $r=0.85$, $p<.001)$.

\section{Data analysis}

We based our analytic strategy on the assumption that the three groups - from low-risk to high-risk and from high-risk to user status represented a continuum of increasing risk to use steroids. Thus, overall differences among the three groups were first tested by chisquare tests and analyses of variance for categorical and continuous variables. respectively. When overall differences were significant. we looked for significant contrasts between the low-risk and high-risk groups, and between the high-risk and steroid user groups. All tests were two-tailed. The Fisher's exact test was used instead of a chi square test when cell sizes were too small. Using these analytic lools, we identified a number of variables that distinguished the high-risk group from the other two groups. We then employed stepwise. multiple regression techniques to determine the best predictor variables that distinguished high-risk nonusers from each of the other two groups.

Results

\section{Group comparisons:}

Demographically, the sample was composed of young. single white men who had completed two years of college (Table 1). The high-risk group was significantly younger than both the low-risk group and the users. The three groups did not difler in race or education. but the high-risk group contained more students. had less employment and lower incomes. and all had never married. After adjusting for age. these demographic differences were not significant. except for unemployed student status.

In terms of training characteristics (Table 2). the high-risk group had been lifing weights for a significantly shorter duration ( $\bar{X}=3.4$ years) than the steroid users $(\bar{X}=7.3$ years $)$, an effect that persisted even after adjusting for age. The high-risk group $(\bar{X}=9.9 \mathrm{~h})$ spent significantly more time than the low-risk group $(\bar{X}=7.6 \mathrm{~h})$, and as much time as the steroid users $(\bar{X}=10.6 \mathrm{~h})$, lifting weights cach week. The likelihood of training for a bodybuilding competition increased progressively when comparing groups in order from low-risk (4\%) and high-risk (24\%) to steroid-using $(44 \%)$ status $\left(X^{2}=21.04\right.$. df $=2, p<.(001)$. However. the contrast between the latter two groups only approached significance $\left(X^{2}=3.42 . d f^{\prime}=1\right.$. $p=.064)$. All three groups $(6.3 \%)$ equivalently responded that they were training to improve 
Table 1

Demographic Characteristics

\begin{tabular}{|c|c|c|c|c|c|}
\hline Variable & $\begin{array}{l}\text { Low-risk } \\
\text { nonusers } \\
(n=50)^{h}\end{array}$ & $\begin{array}{l}\text { High-risk } \\
\text { nonusers } \\
(n=35)^{\mathrm{h}}\end{array}$ & $\begin{array}{c}\text { Steroid } \\
\text { users } \\
(n=49)^{\mathrm{h}}\end{array}$ & $\begin{array}{c}\text { Low-vs } \\
\text { high-risk } \\
\text { groups } \\
\text { (p value) }\end{array}$ & $\begin{array}{c}\text { High-risk } \\
\text { group vs } \\
\text { users } \\
(p \text { value })^{\circ}\end{array}$ \\
\hline Age (years) & $23.4 \pm 6.0$ & $20.4 \pm 2.9$ & $24.4 \pm 5.7$ & .009 & $<.001$ \\
\hline Race ( $\%$ white) & 84.8 & $94.1^{-}$ & $91.5^{-}$ & n.s. & n.s. \\
\hline $1 / 0$ Never married & 87.5 & 100 & 76.6 & $.037^{d}$ & $.002^{d}$ \\
\hline Education (years) & $14.8 \pm 2.7$ & $14.0 \pm 2.6$ & $14.5 \pm 2.2$ & n.s. & n.s. \\
\hline$\%$ Employed & $56.0^{-}$ & 37.1 & 77.6 & n.s. & $<.00 \mathrm{l}$ \\
\hline$\%$ Students & 43.8 & 51.4 & 14.9 & n.s. & $<.001$ \\
\hline Income (\$) & $\begin{array}{l}17,661 \pm \\
21,056\end{array}$ & $\begin{array}{l}8,814 \pm \\
7,582\end{array}$ & $\begin{array}{l}19,461 \pm \\
14.782\end{array}$ & $.035^{4}$ & $.011^{\mathrm{d}}$ \\
\hline
\end{tabular}

Mean $\pm S D$ is presented for continuous variables.

${ }^{\mathrm{h}}$ Sample size is smaller for some variables due to missing responses.

"The $p$ values are for contrasts between two groups and were determined if the overall $X^{2}$ test or ANOVA was significant at the $p<.05$ level. The overall test was not significant when both columns are marked "n.s." Fisher's exact test was used when cell sizes were too small.

Not significant after adjusting for age.

their performance in other sports, and almost all respondents $(96 \%)$ affirmed that they lifted weights to improve physical appearance.

Weight lifters were asked to check "yes" for each of 15 non-steroidal substances that they had used for training: protein supplements, amino acids, vitamins, diet pills, caffeine, cocainc, amphetamines, growth hormone, growth hormone releasers, human chorionic gonadotropin, natural testosterone releasers, diuretics, tamoxifen, Mexican sarsaparilla, and "other". The number of these substances used progressively and significantly increased when comparing the low-risk nonusers $(\bar{X}=2.3)$ to the high-risk nonusers $(\bar{X}=3.9)$ and the steroid users $(\bar{X}=5.7)$ (Table 2$)$. The three groups did not differ in their use of cocaine or amphetamines, tobacco, or alcohol; and about three-fourths of the nonusers had tried marijuana (a question not asked of the steroid users). The four CAGE questions, which are used to screen for alcoholism (Ewing, 1984), detected substantial but equivalent rates of alcohol problems among the three groups (Table 2). All three groups had considerable but equivalent alcohol intakes ( 89 drinks) when asked for the most drinks they consumed in one day in the past 30 days.

Body image significantly distinguished the high-risk group from the other two groups (Table 3). When asked, "Do you ever feel like you are not big enough?" subjects could respond on a 5-point scale; and we grouped together the responses of "all of the time" and "most of the time" in our analysis of "feels not big enough". Using this method, $71 \%$ of the high-risk group felt like they were "not big enough", compared to $38 \%$ of the steroid users and $21 \%$ of the low-risk group $\left(X^{2}=21.64\right.$, $\left.d f=2, p<.001\right)$. When asked, "How satisfied are you with your body and physical appearance?" subjects could respond on a 4 point scale ranging from "extremely satisfied" to "not so satisfied". We grouped the responses of "extremely satisfied" and "very satisfied" together, and found that fewer high- 
Table 2

Training Characterivies and Suhstance low

\begin{tabular}{|c|c|c|c|c|c|}
\hline Variable" & $\begin{array}{l}\text { Low-risk } \\
\text { nonuscrs } \\
(11-50)^{1}\end{array}$ & $\begin{array}{l}\text { lligh-risk } \\
\text { nomusers } \\
(1=35)^{\prime \prime}\end{array}$ & $\begin{array}{c}\text { Steroid } \\
\text { users } \\
(n=49)^{\mathrm{h}}\end{array}$ & $\begin{array}{c}\text { Low- w } \\
\text { High-risk } \\
\text { groups } \\
\text { (j) valuce }\end{array}$ & $\begin{array}{c}\text { High-risk } \\
\text { group is } \\
\text { users } \\
\text { (f! values) }\end{array}$ \\
\hline \multicolumn{6}{|l|}{ Traming characeretistes } \\
\hline Ycurs lifting weights & $+2 \pm 3.2$ & $34+20$ & $7.3 \pm 4.4$ & $11 . .$. & $<.001$ \\
\hline Hours week of lifing & $7.6+3.1$ & $9.9+3.8$ & $10.6 \pm 3.9$ & 005 & n.s. \\
\hline \multicolumn{6}{|l|}{ Recrson for trasining } \\
\hline - Bodybuilding comperition $\left({ }^{\circ}, 0\right)$ & $+.1)$ & 23.5 & +3.5 & (1) 13 & $(.064)$ \\
\hline - Other sports $\left({ }^{\circ} \circ\right)$ & 68.0 & 65.7 & 57.1 & ni.s. & nl.s. \\
\hline - Physical appearance ("o) & $9 \leqslant .0$ & 1) 4.3 & 95.9 & n.s. & $11 \ldots$. \\
\hline \multicolumn{6}{|l|}{ Substancerase } \\
\hline $\begin{array}{l}\text { Nonsteroidal substancos used for } \\
\text { training (\#) }\end{array}$ & $2.3+2.3$ & $3.9+2.1$ & $5.7 \pm 2.3$ & .190 .3 & 001 \\
\hline (igarette smoker (" & 2.1 & 5.7 & 4.3 & $n x$ & $11 .$. \\
\hline (hens lobacio $(0 \%)$ & 5.5 & 9.1 & 13.3 & $n \ldots$ & $11 . s$. \\
\hline$C A\left(j E x c o r e \geqslant 21^{\circ} 0\right)$ & 27.7 & $3+\ldots$ & 30.4 & n ... & $11 . s$ \\
\hline Maximum drinkis alay & $8.0 \perp 8.0$ & $5.5 \pm 0.6$ & $9.2+7.9$ & $n 1 \ldots$. & $11 \ldots$ \\
\hline Tried marijuana $\left(0_{0}\right)$ & 71.4 & $77 . \overline{1}$ & nol asked & $11 \ldots$ & \\
\hline $\begin{array}{l}\text { Cocaine or ampletamine used for } \\
\text { training }\left({ }^{\circ}\right)\end{array}$ & 2.0 & 2.4 & $\therefore .2$ & 1i.s. & $11 . S$. \\
\hline
\end{tabular}

Mean $\pm S D$ is presented for continuous valriables.

"Sample sise is moller for some variables due to missing responses.

"The p values are for contrasts between two groups and were detemined it the overall flest or A voVA was significant al the $p<.05$ level. The overall lest was $n$ ol signilicant when both columns are marked "n.s." Fisher" exact test was used when eell sizes were 100 small. Parentheses mark p ralues that approached significance (p) 6.07 ). as these variables were entered into the regression antalyses.

risk nonusers $(26 \%)$ than steroid users $(55 \%)$ were satisfied with their bodies and physical appearance $\left(X^{2}=6.63 . d f=1, p=.010\right)$. The contrast between the high-risk group $(26 \%)$ and the low-risk group $(46 \%)$ for satisfaction with body and physical appearance approached significance $\left(X^{2}-3.50\right.$. df $\left.=1 . \rho=.061\right)$. Of interest, the high-risk group nas signilicantly shorter than the low-risk group (albeit by only 1.5 inches); and although they weighed about the same as the low-risk group, they weighed significantly (23 lb) less than the steroid users (Table 3 ).

Knowing another steroid user increased progressively and significantly from $58 \%$ in the low-risk group to $83 \%$ in the high-risk group and $98 \%$ in the steroid users (Table 3). Nearly two-thirds of the nonusers reported that they could obtain steroids either very or somewhat easily, which did not differ between the wo groups. Finally, the nonusers were asked it they thought steroids could cause cach of 19 negative consequences: liver disease, heart atlacks. hardening of the arteries, high blood pressure, acne, breasts to grow in men, death. episodes of rage hallucinations, depression. psychotic reactions, mania, problems with sex drive, impotence, suicidal thinking. hatir loss, testicles to shrink, conlused thinking. and addiction. The number of perceived negative consequences was high for both groups (12 to 14) and did not differ between them (Table 3). However, the high-risk group endorsed two of the consequences (problems with sex drive and testicular atrophy) significantly 
Table 3

Body Assessments and Other Factors

\begin{tabular}{|c|c|c|c|c|c|}
\hline Variablei & $\begin{array}{l}\text { Low-risk } \\
\text { nonusers } \\
(n-50)^{\mathrm{h}}\end{array}$ & $\begin{array}{l}\text { High-risk } \\
\text { nonusers } \\
(n-35)^{\mathrm{h}}\end{array}$ & $\begin{array}{c}\text { Steroid } \\
\text { users } \\
(n-49)^{\mathrm{h}}\end{array}$ & $\begin{array}{l}\text { Low-vs } \\
\text { high-risk } \\
\text { groups } \\
(p \text { valuc })^{c}\end{array}$ & $\begin{array}{c}\text { High-risk } \\
\text { groups vs } \\
\text { users } \\
\text { (p) value) }\end{array}$ \\
\hline \multicolumn{6}{|l|}{ Body assessments } \\
\hline Feels not hig enough $(\%)$ & 20.8 & 71.4 & 38.1 & $<.001$ & .004 \\
\hline $\begin{array}{l}\text { Satisfied with body and physical } \\
\text { appearance }(\%)\end{array}$ & 45.8 & 25.7 & 54.8 & $(.061)$ & .010 \\
\hline Weight (Ib) & $182.6 \pm 24.6$ & $179.1 \pm 22.2$ & $202.1 \pm 31.2$ & n.s. & $<.001$ \\
\hline Height (inches) & $71.3 \pm 2.7$ & $69.8 \pm 3.0$ & $70.8 \pm 3.4$ & .032 & n.s. \\
\hline \multicolumn{6}{|l|}{ Oher factors } \\
\hline Knows steroid user $(\%)$ & 58.0 & 82.9 & 98.0 & .015 & .019 \\
\hline Easy to obtain (" $\%$ yes) & 65.3 & 65.7 & not asked & n.s. & $\cdots$ \\
\hline $\begin{array}{l}\text { No. of perceived negative } \\
\text { consequences }(0.19)\end{array}$ & $12.7 \pm 6.1$ & $13.7 \pm 5.6$ & not asked & n.s. & \\
\hline \multicolumn{6}{|l|}{ Steroids canter: } \\
\hline - acne (\% yes) & 71.4 & 88.2 & not asked & $(.068)$ & \\
\hline - problems with sex drive (\% yes) & 65.3 & 87.9 & not asked & .022 & \\
\hline - hair loss (\% yes) & 59.2 & 79.4 & not asked & $(.053)$ & \\
\hline - testicles to shrink (\% ycs) & 65.3 & 88.2 & not asked & .018 & \\
\hline - death $(\%$ yes $)$ & 81.6 & 88.2 & not asked & n.s. & \\
\hline
\end{tabular}

"Mcan $\pm S D$ is presented for continuous variables.

"Sample size is smaller for some variables due to missing responses.

"The $p$ values are for contrasts between two groups and were determined if the overall $X^{2}$ test or ANOVA was significant at the $p<.05$ level. The overall test was not significant when both columns are marked "n.s." Fisher"s exact test was used when cell sizes werc too small. Parentheses mark $p$ values that approached significance $(p<.07)$, as these variables were entered into the regression analyses.

more often than the low-risk group, whereas the low-risk group endorsed none of the consequences significantly more often (Table 3 ).

\section{Regression analyses}

We employed stepwise, multiple regression techniques to select traits that best predicted how the high-risk group differed from the other two groups. Because the high-risk group was significantly (3-4 years) younger than the other two groups, we insured that age remained in the regression model. We entered other variables into the regression procedures that either differed significantly between groups or approached significance $(p<.070)$. We excluded some demographic variables for entry (marital status and income), because they neither differed significantly between groups nor approached significance after adjusting for age.

The following 12 variables were entered to predict status as a low-or high-risk nonuser: age, weekly hours spent training, training for a bodybuilding competition, number of nonsteroidal substances used for training, satisfaction with body and physical appearance, feeling not big enough, height, knowing a steroid user, and thinking that steroids cause problems with sex drive, testicular atrophy, hair loss, and acne. The best predictors when 
Table 4

Models for Predicuing Risk (iroup

\begin{tabular}{|c|c|c|c|c|}
\hline Variable & Parameler & $\mathrm{SE}$ & Wald $X^{2}$ & p value \\
\hline \multicolumn{5}{|l|}{ Low-risk es highl-risk groups } \\
\hline Intercept & -19.95 & 8.14 & 0.000 & .014 \\
\hline Age & 0.15 & 0.09 & 2.72 & .100 \\
\hline Fecls not big enough & 1.06 & 0.33 & 10.40 & 001 \\
\hline Height & -0.26 & 0.10 & 6.49 & 011 \\
\hline Knows sleroid user & -1.73 & 0.68 & 6.46 & .011 \\
\hline \multicolumn{5}{|l|}{ High-risk en aser aroups } \\
\hline Inlercept & 14.33 & 4.64 & 9.53 & .002 \\
\hline Age & -0.27 & 0.11 & 6.36 & .117 \\
\hline Student status & 2.33 & 0.84 & 7.65 & .006 \\
\hline Numsteroidal substances used lou taininge (\#) & $\ldots 0.78$ & 0.23 & 11.08 & 001 \\
\hline Fecls not big enough & 0.96 & 0.47 & 4.25 & .039 \\
\hline Weight & -0.05 & 0.016 & 8.93 & .003 \\
\hline
\end{tabular}

age was included were feeling not big enough, height, and knowing a steroid user (Table 4). The predictors correctly classitied $77 \%$ of subjects (goodness of tit $X^{2}=38.14, a t f=4$, $p<.001)$. The following 10 variables were entered to predict status as a high-risk nonuser or steroid user: age, employment, student status, duration of weight lifting activity, training for a bodybuilding competition. number of nonsteroidal substances used for training. satisfaction with body and physical appearance, feeling not big enough, weight. and knowing a steroid user. The best predictors when age was included were student status, number of nonsteroidal substances used for training, feeling not big enough, and weight (Table 4). The predictors correctly classified $82 \%$ of subjects (goodness of fit $X^{2}=59.19 . d f=5$, $p<.001)$.

\section{Discussion}

Weight lifters who were thinking about using steroids (high-risk group) could be distinguished from other nonusers by (a) younger age. (b) more hours each week spent lifting weights, (c) greater likelihood of training for a bodybuilding competition, (d) more nonsteroidal substances used for training, (e) feeling not big enough, (f) smaller height, (g) greater acquaintance with steroid users, and (h) greater awareness of certain side effects of steroid use. When these factors were entered into a regression analysis that controlled for alge, the best predictors of high-risk status were feeling not big enough. knowing a steroid user, and shorter height.

Weight lifters who were thinking about using steroids (high-risk group) could be distinguished from steroid users by (a) younger age, (b) student status. (c) less employment. (d) shorter duration of weight lifting activity. (e) less nonsteroidal substances used for training. (f) feeling not big enough. (g) less satisfaction with body and physical appearance. (h) lower body weight. and (i) lesser acquaintance with steroid users. When these factors were entered into a regression analysis that controlled for age, the best predictors of highrisk status were student status, number of nonsteroidal substances used for training. feeling not big enough. and weight. 
Overall, feeling not big enough was a consistent predictor of high-risk status. To some extent the high-risk group really was smaller in actual height and weight, but the subjective experience of feeling not big enough persisted as a predictor even after entering height and weight into the respective regression analyses. Anabolic-androgenic steroids probably appeal to individuals who do not feel big enough. because they can produce significant increases in lean body mass (Forbes et al., 1992). Komoroski and Rickert (1992) reported that steroid users were significantly more satisfied with their body image than nonusers. We previously reported that body image dissatisfaction predicted intensified patterns of steroid use among the 49 steroid users included in the present study (Brower et al., 1991). An intriguing interpretation of these data, then, is that steroids do work to increase satisfaction with body size, and that dissatisfaction with body size may contribute significantly first to the risk of using steroids and then to the risk of using steroids intensively.

The values of some variables (training for a bodybuilding competition, number of nonsteroidal substances used for training, and knowing a steroid user) progressively increased when comparing the low-risk group to the high-risk group and the high-risk group to the steroid users. Although the group comparisons are cross-sectional, the gradients observed in these three variables give the appearance of movement from low-risk status to actual steroid use as weight lifters become more involved in bodybuilding, trying substances, and knowing other users. Nevertheless, only a longitudinal study of weight lifters can properly track the antecedents of steroid use and the movement suggested by our data.

We did not find group differences in the use of addictive substances (tobacco, alcohol, marijuana, stimulants). Alcohol consumption and problems were substantial across groups. The lifetime prevalence of marijuana use was higher in the nonusers $(74 \%)$ than in a national sample of college students studied in $1989(51 \%)$ (Johnston et al., 1992), although the two groups are not necessarily comparable. Our sample used tobacco infrequently, but the trend to chew rather than smoke tobacco has been described in other athlete populations (DuRant et al., 1993). Overall, we found substantial use of alcohol and marijuana in our sample, but did not find support for the notion that alcohol, marijuana, or tobacco served as gateway drugs to use steroids. If anything, nonsteroidal performance aids appeared to function as gateway drugs, probably because they establish a mind-set for chemical enhancement without providing very effective results.

Nearly two-thirds of the nonusers agreed that they could easily obtain steroids, and availability did not distinguish the risk groups. Both risk groups were also fairly wellinformed about the health risks of using steroids, and they could recognize more than 12 negative consequences. In fact, the high-risk group appeared somewhat more informed than the low-risk group. It is possible that the high-risk group, which was thinking about using steroids, deliberately sought information about steroids before deciding to use. However, the knowledge of the high-risk group regarding adverse consequences did not prevent them from thinking about using. Indeed, $88 \%$ of the high-risk group thought steroids could cause death. Other studies also have found that determined individuals will either use steroids or consider their use despite actual and perceived negative consequences (Brower et al., 1991; Yesalis et al., 1990). Moreover, prevention studies have shown that providing information only about negative consequences provides no benefit and may 
paradoxically increase interest in trying steroids (Bosworth et al.. 1988; Goldberg et al.. 1991). Nevertheless, while certain subgroups are not realdily deterred by negative consequences, trends in large, national samples suggest that perceived risks lead to reduced use of drugs like cocaine (Bachman et all. 1990). Similarly. the University of Michigan Monitoring the Future study found a statistically significant decline in the annual prevalence of steroid use among high school seniors from $1.9 \%$ in 1989 to $1.1 \%$ in 1992 . while the perceived risk of harm signiticantly increased from $64 \%$ to $71 \%$ over the same lime period (Johnston et al.. 1993).

Several limitations of the study are emphasized. First. considerable selection bias was possible. because a small number of gymnasiums were selected by convenience and systematic sampling of subjects in those gymnasiums did not occur. We have no information on the characteristics of gym users who did not participate in the study. so we do not know how representative the sample was of this or other populations. Clearly, non-whites were poorly represented in the sample, which is important because national data indicate that minority groups are equally or more likely to use steroids than whites in this comntry (Buckley et al., 1988: Yesalis et al., 1993). It is also possible that steroid users were undersampled because the illicit nature of the activity may have deterred study participation Furthermore. we studied a community sample of weiglnt-lifting men, and other factors may better explain the risk to use steroids in women. students, and elite athletes. Thus. our results annot be generalized withoul caution. and they serve mainly to generate hypotheses about risk factors. Second, there are a number of possible risk fictors for steroid use that we made no attempt to assess, such as the details of athletic competition, family history of substance abuse, psychopathology. and other risk-taking behaviors. Other studies will need to examine these potential lactors. Third. we relied on self-report withoul corroboration by collateral informants, physioal measurements, or urine testing. Agatinst these mealsures. the validity of responses to the guestionnatire is unknown. We did obtain evidence of reliable responding as measured by repeated questions. and the guarantec of anonymity may have facilitated truthful responses. In addition. pulot testing of the questionnatire indicated that subjects understood the guestions clearly and responded accordingly. Nevertheless. pilot testing occurred on a very small number of subjects. and study subjects maty have minimized their actual or potential use of illicit drugs. Thus, luture studies should employ methods to corroborate self-report data. Fourth. cross-sectional research does not provide information about the temporality of antecedent factors, and the differences we found at best represent correlates of risk and not causative factors for steroid use. Finally, body imatge disturbance. perhaps the most robust finding in our study, was measured in only a limited fashion. The phratse, "feeling not big enough", caln refer to height, weight. strength. body image. selfesteem. or a feeling of personal power. Furthermore. the inlluence of a workout on body image is unknown. yet subjects completed the survey either before or after their workouts which maly have introduced additional variability. Future studies should employ standardiced, carefully timed. and more in-depth assessments of body image in steroid users and other weight lifters (Thompson. 1990).

In conclusion, we found that weight-lifting men who were thinking about using steroids (high-risk nonusers) differed from other male weight lifters predominantly in terms of body image. High-risk nonusers were most likely to leel not big enough when compared to both 
steroid users and other nonusers. When groups were compared along a continuum from low risk to high risk and from high risk to actual use, increasing amounts of competitive bodybuilding, nonsteroidal performance-enhancers tried, and steroid-using acquaintances were reported. In regression analyses, body image distinguished high-risk nonusers from each of the other two groups, steroid-using acquaintances distinguished high-risk front low-risk nonusers, and use of nonsteroidal performance-enhancers distinguished high-risk nonusers from users. Taken together, these findings suggest that body image, peer group influences, and the use of nonsteroidal performance-enhancers may be particularly important risk factors for steroid use among male weight lifters in community gymnasiums. If confirmed by further research. then prevention efforts should focus on enhancing body image, resisting peer group influences, and alternatives to "gateway" performanceenhancers.

Acknowledements The authors wish to acknowledge the contributions of Drs Patrick M. O'Malley, George A. Eliopulos, and Thomas P. Beresford. Joel Dood assisted with statistical analyses. This work was supporled in part by grant $\mathrm{AA} 07378$ from the National Institute on Alcohol Abuse and Alcoholism.

\section{References}

Bachman. J. G., Johnston. L. D., \& O'Malley. P. M. (1990). Explaining the recent decline in cocaine use among young adults: further evidence that perceived risks and disapproval lead to reduced drug use. Jommal of $/ / l^{\prime} a / h$ and Social Behariom, 31, 173184

Bahrke. M. S. Yesalis. C. E.. \& Wright. J. E. (1990). Psychological and behavioural effects of endogenous testosterone levels and anabolic-androgenic steroids among males: a revicw. Sports Medicine. 10, 303.337.

Bosworth. E., Bents, R.. Trevisan, L.. \& Goldberg. L. (1988). Anabolic steroids and high school athletes. Medicino and Srionce in Sports and Exereise, 20, S3.

Brower, K. J. (1992). Anabolic steroids: addictive, psychiatric, and nedical consequences. Amoticam foumal on Addictions. 1, 100114

Brower. K. J., Blow. F. C., Young. J. P., \& Hill, E. M. (1991). Symptoms and correlates of anabolic-androgenic steroid dependence. British Joumal of Addiction, 86, 759-.768.

Buckley. W., Yesalis. C.. Friedl, K.. Anderson. W., Streit, A., \& Wright. J. (1988). Estimated prevalence of anabolic steroid use among male high school seniors. Jownal of the American Medical Association, 260, 3441 3445

Council on Scientific Aftairs. (1990). Medical and nonmedical uses of anabolic-androgenic steroids. Jommat of the American Modical Association. 264, 2923--2927.

DuRant, R. H.. Rickert. V. I., Seymore Ashworth. C.. Newman, C., \& Slavens. (i. (1993). Use of multiple drugs among adolescents who use anabolic steroids. New England Journal of Medicine, 328, 922-926.

Ewing. J. A. (1984). Detecting alcoholism: the CAGE questionnaire. Joumal of the American Medical Aswociation. 252, 19051907

Forbes. G. B.. Portit. C. R.. Herr. B. E., \& Griggs. R. C. (1992). Sequence ol changes in body composition induced by testosterone and reversal of changes after drug is stopped. Joumal of the American Medical Assoctation, 267, 397.399.

Goldberg. L., Bents. R., Bosworth. E., Trevisan. L., \& Elliot, D. L. (1991). Anabolic steroid education and adolescents: do scare tactics work? Pediatrics. 87, 283286.

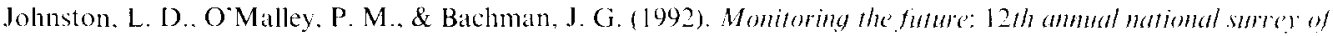
American college shadents. Ann Arbor, MI: University of Michigan News and Information Services.

Johnston, L. D., O`Malley, P. M.. \& Bachman. J. G. (1993). National survey results on drug use from monitoring the future study, 1975 1992. Volume I, secondary school students (NIH Publication No. 93 397). Rockville MD: National institute on Drug Abuse.

Komoroski, E. M., \& Rickert, V. I. (1942). Adolescent body image and attitudes to anabolic steroid use. American Joumat of Discases of Children. 146, 823-828.

Krowchuk. D.. Anglin. T., Goodfellow. D.. Stancin. T.. Williams. P.. \& Zimet. G. (1989). High school athletes and the use of ergogenic aids. Americun Jommal of Discases of Children. 14.3, $486,489$. 
Pope, H. Kat1, D.. \& (hampoux, R. (1988). Anabolic-androgenic steroid use among 1.010 college men. The Phisician and Sportsmodicinc, 1607).7581.

Su. T. P.. Pagliaro. M.. Schmidt. P. J.. Pickar. D.. Wolkowitz. O.. \& Rubinow. D. R. (1993). Neuropsychiatric effects of anabolic steroids in male normal volunteers. Jommal of the American Medical Ascociation, 269, 2760 2764.

Thompson. J. K. (1990). Bodl image disturhance: assessmemt and weamem. New York, NY: Pergamon Press.

Yesalis, C. E. (1992). Epidemiology and patterns of anabolic-androgenic storoid use. Prichiatric Amuls, $22(1), 7$. 18.

Yesalis, C. E., Kennedy, N. J.. Kopstcin A. N., \& Bahrke, M. S. (1993). Anabolic-androgenic steroid use in the United States. Joumal of the American Medical Association, 270, 12171221.

Yesalis, C. E.. Vicary, J. R., Buckley, W. F., Streit, A. L.. Kat/, D. L., \& Wright. J. E. (1990). Indications of psychological dependence among anabolic-androgenic steroid abusers. National Insiature on Drag Ahuse Research Monograph Seric's, 102, 196214. 